\title{
BMJ Open Knowledge and motivations of researchers publishing in presumed predatory journals: a survey
}

\author{
Kelly D Cobey, ${ }^{1,2}$ Agnes Grudniewicz, ${ }^{3,4}$ Manoj M Lalu, ${ }^{\odot 5}$ Danielle B Rice, ${ }^{\oplus, 7}$ \\ Hana Raffoul, ${ }^{8}$ David Moher ${ }^{\circ}$
}

To cite: Cobey KD, Grudniewicz A, Lalu MM, et al. Knowledge and motivations of researchers publishing in presumed predatory journals: a survey. BMJ Open 2019;9:e026516. doi:10.1136/ bmjopen-2018-026516

- Prepublication history for this paper is available online. To view these files, please visit the journal online (http://dx.doi. org/10.1136/bmjopen-20180256516).

Received 6 September 2018 Revised 6 February 2019 Accepted 18 February 2019

Check for updates

(C) Author(s) (or their employer(s)) 2019. Re-use permitted under CC BY-NC. No commercial re-use. See rights and permissions. Published by BMJ.

For numbered affiliations see end of article.

Correspondence to

Dr David Moher;

dmoher@ohri.ca

\section{ABSTRACT}

Objectives To develop effective interventions to prevent publishing in presumed predatory journals (ie, journals that display deceptive characteristics, markers or data that cannot be verified), it is helpful to understand the motivations and experiences of those who have published in these journals.

Design An online survey delivered to two sets of corresponding authors containing demographic information, and questions about researchers' perceptions of publishing in the presumed predatory journal, type of article processing fees paid and the quality of peer review received. The survey also asked six open-ended items about researchers' motivations and experiences.

Participants Using Beall's lists, we identified two groups of individuals who had published empirical articles in biomedical journals that were presumed to be predatory. Results Eighty-two authors partially responded ( $14 \%$ response rate $(11.4 \%[44 / 386]$ from the initial sample, $19.3 \%[38 / 197]$ from second sample) to our survey. The top three countries represented were India $(n=21,25.9 \%)$, USA $(n=17,21.0 \%)$ and Ethiopia $(n=5$, $6.2 \%)$. Three participants (3.9\%) thought the journal they published in was predatory at the time of article submission. The majority of participants first encountered the journal via an email invitation to submit an article $(n=32,41.0 \%)$, or through an online search to find a journal with relevant scope $(n=22,28.2 \%)$. Most participants indicated their study received peer review $(n=65,83.3 \%)$ and that this was helpful and substantive $(n=51,79.7 \%)$. More than a third $(n=32,45.1 \%)$ indicated they did not pay fees to publish.

Conclusions This work provides some evidence to inform policy to prevent future research from being published in predatory journals. Our research suggests that common views about predatory journals (eg, no peer review) may not always be true, and that a grey zone between legitimate and presumed predatory journals exists. These results are based on self-reports and may be biased thus limiting their interpretation.

\section{INTRODUCTION}

In the current scholarly landscape, the threat of presumed predatory journals (ie, journals that display deceptive characteristics, markers or data that cannot be verified because there is no gold standard as to what defines

\section{Strengths and limitations of this study}

The survey specifically explored researchers' motivations to publish in predatory journals

- The survey targeted biomedical researchers where dissemination of preclinical and clinical outcomes may affect health services and patient care

- The survey is limited by a low response rate from participants

predatory journals) adds a further layer of complexity to the journal selection process. The presumption of predation is on our part because the journals we examined have signs, such as fake journal impact factors, suggesting they fail to meet expected best journal standards. There is a sense that predatory journals exploit the open access (OA) publishing model (in which authors typically pay a fee to publish to ensure that their work is publicly and freely accessible), often by 'spamming' researchers ${ }^{12}$ with offers of rapid publication at a much lower cost than legitimate OA journals, or without acknowledging upfront that accepted manuscripts are subject to publication fees. ${ }^{3}$ Subsequently, it is suspected that these journals conduct frivolous (or no) peer review and often accept and publish manuscripts without any editing or editorial oversight whatsoever. ${ }^{5}$

Without action by relevant stakeholders, the potential for predatory journals to continue to penetrate the scholar community is great. ${ }^{67}$ Understanding what predatory journals are ${ }^{8}$ and what motivates researchers to submit to and publish in these journals is essential to preventing future submissions. Failure to address predatory journals means that they will continue to contribute to the waste and inefficiency in dissemination. Public broadcasters in Germany undertook a review of researchers to determine the presence of German scientists publishing in predatory journals (https:// 
www.the-scientist.com/news-opinion/german-scientistsfrequently-publish-in-predatory-journals-64518). More than 5000 German scientists were reported as having published papers in predatory journals where the peer review process did not occur. Many of the projects were also receiving public funding. Further, a recent study examined more than 45000 Italian Curricula Vitae (CVs) and found that approximately $5 \%$ contained research thought to be published in predatory journals. ${ }^{9}$ A related survey of those researchers who published in predatory journals (response rate 54\%) found that about 33\% had colleagues suggest a predatory journal as an option for submission, $27 \%$ of researchers submitted their work to a predatory journal in response to an email invitation, while $12 \%$ said their decision for where to submit their manuscript was linked to a conference presentation. A survey by Kurt ${ }^{10}$ obtained responses from 96 authors who had published in 50 randomly selected journals on Beall's journal list. The respondents were from a range of scientific fields, and the survey was predominantly composed of open-ended questions analysed qualitatively. Kurt reported that the reason these individuals published in predatory journals were captured in four themes: social identify threat, unawareness, high pressure and lack of research proficiency. These findings provide initial evidence for how researchers come to submit their papers to predatory journals, but they do not explicitly consider a broad range of motivations. In addition, it is likely that there are nuances between scientific disciplines, which may have different norms and expectations pertaining to publishing scholarly activity.

Here, we seek to examine the motivations and experiences of biomedical researchers who have submitted to predatory journals. To address the prevalence of these and other motivations, we conducted a multinational survey of researchers who published in predatory biomedical journals.

\section{METHODS}

We conducted an online survey to obtain information about the motivations and experiences of researchers who have published in potentially predatory biomedical journals.

\section{Identifying participants}

Initially, we identified a sample of participants for our survey by using an existing dataset of 1907 articles $^{7}$ that had been published in predatory biomedical journals. This sample was derived in a previous study examining a random selection of articles published in journals listed on Beall's lists of 'potential, possible or probable' predatory journals. ${ }^{11}$ The dataset included the email contact details for the corresponding authors of each paper when available. From the total group of 1907 articles, we selected those, and the related author details, that were coded as having the following research designs: randomised controlled trial $(n=94)$, observational cohort $(n=180)$ or a preclinical research-based article $(n=201)$. These study designs were selected to provide a combination of clinical and preclinical research, and in an effort to achieve a response from approximately 200 participants. We had anticipated a response rate of $\sim 40 \%$, given the rates of response from previous work. ${ }^{9} 10$ This sampling procedure is consistent with the methods described in the original study protocol that was posted prior to data collection on the Open Science Framework (OSF): https://osf.io/ wgm7f/. A low response rate (see results) ensued. We considered that one reason for the modest response rate to the initial survey was that the authors sampled for our survey had been gathered in a study published in 2015 . It was thought that obtaining a more recent sample of authors may result in a greater response rate. Therefore, after seeking a revision in ethical approval, we identified a second sample of potential authors of predatory journals to survey.

To identify this second sample, we used two approaches. First, we used Beall's lists to identify 100 additional journals. Although Beall removed his lists of predatory journals and publishers from his blog website in early 2017, ${ }^{12}$ his lists have been curated and updated anonymously at this website: https://beallslist.weebly.com/. We extracted all journals on Beall's list of single journal publishers on 5 March 2018. Journal names and their corresponding URL $(n=1310)$ were extracted and then their websites were screened in duplicate (KDC, HR, AG, DBR) to determine if they were active websites, if they published in English, and published research that was predominantly biomedical. We used the Medline definition to define biomedical journals as journals "predominantly devoted to reporting original investigations in the biomedical and health sciences, including research in the basic sciences; clinical trials of therapeutic agents; effectiveness of diagnostic or therapeutic techniques; or studies relating to the behavioural, epidemiological, or educational aspects of medicine ${ }^{13}$ From the journals that met these inclusion criteria $(n=158)$, we then took a random sample, using the (RAND) function in Excel, of 100 journals. Second, we obtained a random sample of 100 biomedical journals published by OMICS (a large publisher of predatory journals ${ }^{1415}$ ). To do so, we selected all journals classified by OMICS as being 'Clinical and Medical Sciences' journals. We de-duplicated journals that were listed more than once, which resulted in 500 unique journals, and using the (RAND) function in Excel, we randomly selected 100 journals.

From the combined random sample of the 200 journals obtained from the single journal publishers on Beall's list $(n=100)$ and from OMICS journals $(n=100)$, reviewers in teams of two (DR, HR, AG, KDC) extracted the most recently posted research article (ie, empirical article; we excluded commentaries, non-systematic reviews, editorials, etc) from each of these journals. They subsequently extracted information including: the year of publication, the corresponding author's name and email address (if identifiable), the corresponding author's country of origin (first listed in affiliation), the article title, and a 
classification of research type (clinical, preclinical, other). If there were no research articles available, the extracted research article did not provide accurate contact details of the corresponding author, or journal website did not function, we replaced the journal with another randomly selected journal $(n=30$ journals replaced from 100 Beall's list journals; $n=14$ journals replaced from OMICS list journals).

\section{Survey administration}

Online survey links were sent to both samples of participants by the primary investigator (KDC) using a standardised recruitment script (available on the OSF: https://osf.io/27bkm/) via a personalised email which specified the participant's name and the title of the identified article. We used MailMerge software to expedite this process. Participants were given 2 weeks to complete the survey. Participants received a standard follow-up email reminder 1 week after the receiving their original invitation to participate.

\section{Survey}

The survey (see https://osf.io/27bkm/) was purposebuilt, administered in English, and distributed using SurveyMonkey. ${ }^{16}$ The survey began with participants completing an online consent and then several items intended to capture respondent demographics (eg, age, gender, country of residency, education level and research speciality area). Subsequently, the survey asked about respondents' research status and publication record. Then, the survey asked respondents about any relevant institutional publication policies, and whether respondents felt pressured by their institution to publish. Several items then addressed the respondents' experience in submitting and publishing the article we captured in our sample of predatory publications. Six open-ended questions then addressed the respondents' decision to publish in the particular journal, when they learnt of its potentially predatory nature and the career implications of the publication. No personal health information or personally identifying information was collected.

When participants completed the survey, they were provided with a generic research code, which they were instructed to send back to the project team via another SurveyMonkey link in which they also reported their email address. The project team subsequently reimbursed participants for their time in the form of a \$C20 online Amazon gift card voucher. Following this method allowed us to successfully reimburse participants without them having to provide personal identification information as part of their survey responses.

\section{Data analysis}

We report descriptive statistics for the characteristics of the participants and summary statistics for quantitative items pertaining to researcher's experiences, knowledge and motivations. Data are reported using means or percentages, as relevant. Given the relatively modest sample, in a deviation from our protocol, we do not provide comparative data illustrating findings by researcher rank, gender, discipline or geographic location. For open-ended survey items, we used conventional content analysis. ${ }^{17}$ Without using preconceived categories, two researchers (AG, DBR) independently identified key themes in the data and then discussed the themes generated until consensus was achieved for themes and subthemes. Key themes are summarised and presented using a narrative synthesis with illustrative quotes and using count data where relevant. Data were exported from the survey software into SPSS where means and percentages were calculated. Qualitative data were analysed in Microsoft Word.

\section{Patient and public involvement}

The focus of this research was the motivations of authors to publish in predatory journals. As such we did not involve patients or the public in the development of the research question or outcomes.

\section{RESULTS}

We sent our survey to a total of 583 potential participants. This number is lower than the combined number of articles identified from the original study database (randomised controlled trial [ $\mathrm{n}=94]$, observational cohort $[\mathrm{n}=180]$ or a preclinical research-based article $[\mathrm{n}=201])$, and the 200 additional sampled articles. This is because not all articles in the original study database contained corresponding email addresses of authors, and in both samples several of the emails sent received bounce-back messages.

A total of 82 participants responded to our survey (44 from the initial sample and 38 from the second sample), although some participants did not complete all items, or chose to skip particular questions. This represents an overall response rate of approximately $14 \%(11.4 \%$ [44/386] from the initial sample and 19.3\% [38/197] from second sample). Demographic characteristics of participants are described in table 1 . We first examined the quantitative survey item results (table 2) and then examined qualitative survey results (table 3 ).

\section{Research institutions}

Five percent $(n=4)$ of survey respondents indicated that their institution has a policy against publishing in predatory journals at the time they published their article. Forty-one percent $(n=32)$ of respondents indicated they felt pressured to publish by their institution, and 25.3\% $(n=20)$ indicated their institution required them to publish a specific number of articles to be considered for tenure and promotion.

\section{Participants' perceptions and experience publishing}

When participants were asked about the article sampled, $46.3 \%(\mathrm{n}=38)$ indicated they did not think the journal they published in was predatory at the time of submission but that they do believe so now, $43.9 \% \quad(n=36)$ felt the 


\begin{tabular}{|c|c|c|}
\hline Characteristic & Sample & $\mathbf{N}$ \\
\hline $\begin{array}{l}\text { Age range } \\
(\text { mean } \pm S D)\end{array}$ & $27-77(45.46 \pm 13.14)$ & 80 \\
\hline Sex, n (\%) & $\begin{array}{l}\text { Male: } 59(72.8) \\
\text { Female: } 21(25.9) \\
\text { Other: } 1(1.2)\end{array}$ & 81 \\
\hline $\begin{array}{l}\text { Top } 3 \text { Nationalities, } \\
\text { n (\%) }\end{array}$ & $\begin{array}{l}\text { India: } 21(25.9) \\
\text { USA: } 17(21.0) \\
\text { Ethiopia: } 5 \text { (6.2) }\end{array}$ & 81 \\
\hline $\begin{array}{l}\text { Research } \\
\text { discipline, n (\%) }\end{array}$ & $\begin{array}{l}\text { Clinical research: } 49(59.8) \\
\text { Preclinical/basic research: } 27 \\
\text { (32.9) } \\
\text { Other: } 6 \text { (7.3) }\end{array}$ & 82 \\
\hline $\begin{array}{l}\text { Research status, } \\
\mathrm{n}(\%)\end{array}$ & $\begin{array}{l}\text { Undergraduate student: } 1 \text { (1.3) } \\
\text { Master's student: } 5 \text { (6.3) } \\
\text { PhD student: } 13 \text { (16.3) } \\
\text { Postdoctoral student: } 3 \text { (3.8) } \\
\text { Assistant/associate/full } \\
\text { professor: } 32 \text { (40.0) } \\
\text { Researcher at research } \\
\text { institute: } 13 \text { (16.3) } \\
\text { Researcher in private sector: } \\
3 \text { (3.8) } \\
\text { Other: } 10 \text { (12.5) }\end{array}$ & 80 \\
\hline $\begin{array}{l}\text { Number of } \\
\text { papers published } \\
\text { within a year of } \\
\text { the presumed } \\
\text { predatory } \\
\text { publication, } n(\%)\end{array}$ & $\begin{array}{l}0: 2(2.6) \\
1-3: 39(50.6) \\
4-6: 20(26.0) \\
7+: 15(19.5) \\
\text { Unknown: } 1(1.3)\end{array}$ & 77 \\
\hline
\end{tabular}

journal they published in was not predatory at the time of submission and maintain this view, while just $3.9 \%(n=3)$ indicated they were aware the journal was predatory at the time of submission. Participants indicated that they became aware of the journal they published in predominantly through direct email invitations to submit from the journal $(\mathrm{n}=32,41.0 \%)$, or through online search for a relevant journal to which to submit $(n=22,28.2 \%)$. Participants indicated that they submitted their article via an online portal on the journal website $(\mathrm{n}=55,70.5 \%)$ or via a direct email to the journal $(n=21,26.9 \%)$. A small percent $(n=2,2.6 \%)$ could not remember how they submitted their article. Slightly more than a third $(n=28$, $35.4 \%$ ) of participants indicated that they had submitted their article to another journal previously. Articles that had been submitted previously had been rejected by a mean of $2.04(0.99 \mathrm{SD})$ journals. A little more than a quarter $(\mathrm{n}=21,27.6 \%)$ of participants said they would publish in the journal in question again, while $36.6 \%$ $(\mathrm{n}=30)$ would not, and $30.5 \%(\mathrm{n}=25)$ were uncertain.

\section{Article processing charges}

Seventy-one of the 82 participants $(86.9 \%)$ responded to the question asking about the fee paid to publish their work. Participants responded in the currency they paid, and these rates were converted using Google to US\$ .
This was done on 7 June 2018, and rates were rounded to the nearest dollar. As currency rates fluctuate, these values should only be considered as estimates. Of the 71 respondents, $45.1 \%(\mathrm{n}=32)$ indicated they did not have to pay an article processing charge to publish their article. Those respondents who did pay a fee $(n=39,54.9 \%)$ paid between US\$ 30-4000 (mean: US\$347.63; median: US\$74; sum: US\$24 682).

\section{Peer review}

The majority $(\mathrm{n}=65,83.3 \%)$ of participants indicated that their paper underwent peer review, while $16.7 \% \quad(n=12)$ indicated it did not. Among those participants who indicated their paper was peer reviewed, $79.7 \% \quad(\mathrm{n}=51)$ indicated they felt the peer review was substantial and helpful, while $20.3 \%$ ( $n=13$ ) indicated it was not. Twenty of the 64 participants $(31.3 \%)$ who indicated that their article underwent peer review, indicated that they would be willing to share the reviews with our research team. Just two eventually forwarded reviews (one of which was a paper proof, not a review), and one author copied the review into the survey.

\section{Qualitative survey results}

Open-ended survey responses were categorised by survey question through content analysis. Themes and subthemes are presented by survey question in table 3 . Below, we provide a narrative synthesis of the data, including motivations and reasons for selecting the journal (survey questions 11 and 13), learning about the journal's predatory nature (questions 12 and 15), career risks (question 14), and evaluating journals for future submissions (question 16).

\section{Motivations and reasons for selecting the journal}

When asked about factors that influenced their decision to submit to the selected journal, participants noted academic and professional factors (eg, publishing pressure, for tenure), factors related to the journal (eg, fit of paper with journal, perception of quality), factors related to the paper published (eg, difficulty in publishing elsewhere due to low originality of the research, previous rejections), desire to disseminate research, invitation from the journal, recommendation from a colleague or personal factors (eg, lack of mentorship, lack of knowledge, personal motivations to publish). In addition to general publishing pressure, seven respondents $(8.5 \%)$ noted that they had to publish as part of degree requirements or did so to support the CV of a student. Fifteen participants $(18.3 \%)$ also reported that they perceived the journal to be of quality for reasons such as: 'reputation of the editor,' 'the journal name seems familiar,' 'well formatted manuscript submission platform,' 'Journal based in the USA, or 'papers already published in this journal by US and German scientists'. Others valued the ease and speed of publication and the journal's low fees, as captured by one response: 'Frustration with number of hours required to publish in standard journals after 
Table 2 Summary of results of quantitative survey items

\begin{tabular}{lll} 
Item & Response & Total N \\
\hline Institutional items & \\
$\begin{array}{ll}\text { Did the primary institution you were based at the year you published } \\
\text { your paper have a written policy for publishing that prohibited predatory }\end{array}$ & $\begin{array}{l}\text { Yes: } 4(5.0) \\
\text { No: } 53(66.3)\end{array}$ \\
$\begin{array}{ll}\text { journals? (n, \%) } & \text { Do not know: } 23(28.7) \\
\begin{array}{l}\text { Did the primary institution you were based at the year you published } \\
\text { your paper make you feel pressured to publish (eg, as part of a degree } \\
\text { requirement or for promotion and/or tenure)? (n, \%) }\end{array} & \text { Yes: } 32(41.0) \\
& \text { No: } 46(59.0)\end{array}$ \\
\end{tabular}

Did the primary institution you were based the year you published Yes: 20 (25.3) your paper have a policy on whether faculty need a specific number of publications to be considered for promotion or tenure? (n, \%)

No: $40(46.5)$

Unsure: 9 (11.4)

Not applicable (eg, I was a student): 10 (12.7)

\section{Participants' perceptions and experience publishing}

We believe the journal in which you published may be a predatory journal. When submitting, were you:

Aware that it was predatory:

$3(3.9)$

Not aware that it was predatory, but now do consider it predatory: 38 (46.3)

Not aware that it was predatory and continue to think it is not predatory: 36 (43.9)

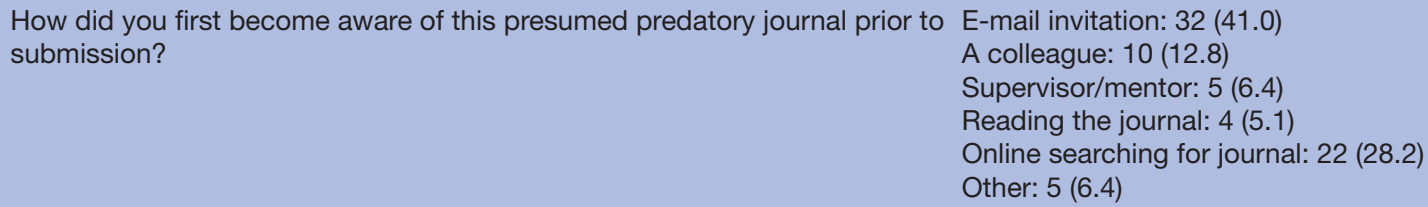

Had the paper you published in this presumed predatory journal been submitted elsewhere previously?

Yes: $28(35.4)$

No: $48(60.8)$

Unsure: 3 (3.8)

$\begin{array}{ll}\text { How many times had the paper been submitted previously? } & 1: 8(28.6) \\ & 2: 12(42.9) \\ & 3: 4(14.3) \\ 4+: 2(7.1) \\ \text { Do not remember: } 2(7.1)\end{array}$

Online submission portal: 55 (70.5)

How was the paper submitted to the journal?

Via email: $21(26.9)$

Other: 2 (2.6)

\begin{tabular}{|c|c|}
\hline $\begin{array}{l}\text { What factors or criteria influenced your decision to submit your manuscript } \\
\text { to this journal instead of another journal (select all that apply)? }\end{array}$ & $\begin{array}{l}\text { I felt it was the appropriate journal for my publication } \\
\text { based on my normal process for selecting a journal } \\
\text { (eg, quality of journal, fit of topic/audience, etc): } 53 \\
(67.1) \\
\text { Adding to my CV quickly for hiring, promotion or } \\
\text { tenure: } 6 \text { (7.6) } \\
\text { Adding to my CV quickly for a grant application: } 0(0.0) \\
\text { I needed to publish a paper quickly as part of my } \\
\text { coursework/programme: } 17 \text { (21.5) } \\
\text { General pressure to publish: } 13 \text { (16.5) } \\
\text { Unable to publish the paper in other journals: } 13(16.5) \\
\text { Other: } 4 \text { (5.1) }\end{array}$ \\
\hline
\end{tabular}

Peer review

\begin{tabular}{|c|c|c|}
\hline Did the paper receive peer review? & $\begin{array}{l}\text { Yes: } 65 \text { (83.3) } \\
\text { No: } 12(16.7)\end{array}$ & 78 \\
\hline Was the peer review substantial and helpful? & $\begin{array}{l}\text { Yes: } 51 \text { (79.7) } \\
\text { No: } 13 \text { (20.3) }\end{array}$ & 64 \\
\hline Where did you obtain money to pay the fee to publish? & $\begin{array}{l}\text { Research grant funding: } 7 \text { (9.6) } \\
\text { University/employer research funding: } 10 \text { (13.7) } \\
\text { Personal money: } 29 \text { (39.7) } \\
\text { Other: } 3 \text { (4.1) } \\
\text { No fee paid: } 24 \text { (32.9) }\end{array}$ & 73 \\
\hline Would you publish in this journal again in the future? & $\begin{array}{l}\text { Yes: } 21(27.6) \\
\text { No: } 30 \text { (36.6) } \\
\text { Uncertain: } 25 \text { (30.5) }\end{array}$ & 76 \\
\hline
\end{tabular}


Table 3 Summary of results of qualitative survey responses

Item Themes (subthemes)

What factors or criteria influenced your decision to submit your manuscript to this journal instead of another journal (eg, hiring, promotion, tenure, requirements to complete degree)?
Academic and professional factors (General; General publishing pressure; As part of current job requirements; For tenure or promotion; Seeking employment/ to get hired; Part of degree requirements (trainees); To support trainees/build CV of trainees; Pressure to publish from trainee)

Factors related to the journal (Paper fit with journal; Perception or appearance of quality; Journal is fast to publish; Publication cost; Ease of publishing; Free editing; Experience with journal)

Recommendation (From colleagues;

From Omni group conference)

Factors related to the paper published (Difficult to publish elsewhere; Limited options for the topic of the paper; Previous rejection(s); The work is good) Desire to disseminate (Wide readership; Open access; International scope) Invitation from journal (Promotional emails)

Personal factors (Lack of mentorship in choosing journal; Lack of knowledge (before predatory journals were common knowledge); Personal pressure/interest to publish)

How did you first become aware that the journal you published in was potentially predatory in nature or may not be scientifically rigorous (eg, I received no peer review although the editor said the article will be published within 24 hours)?

\section{This survey}

Disagree that journal is predatory

Concerns raised by others

Fees (Payment)

Publication process (Peer review; Atypical correspondence; Continued promotion emails)

List of predatory journals

Lack of indexing

Were there other motivations for publishing in No the journal that we have not asked about (eg, Personal factors (Personal satisfaction) salary increase)?

Academic and professional factors (Publication pressure; Self-citation; Part of being a researcher; Salary increase; Promotion in developing countries; To increase programme rankings)

Factors related to the paper published (Topic fit with journal; Low quality of manuscript; Publishing unpublished work; Student paper)

Factors related to the journal (Compared with 'traditional journals')

Desire to disseminate research (Publishing before retirement; Dissemination of work is easy because of the internet)

Supporting new or small journals
Did you see any career risks associated with publishing in this journal (eg, getting caught by a colleague)?

\section{No}

Yes (risks not specified)

Reprimanded by supervisor

Few citations

Damage to reputation

Retraction (Published even after retraction;

Requested retraction)

Continued emails from journal

Missed opportunity for peer review

Has anyone else discussed the potentially No

predatory nature of this journal with you (eg, Yes (Individual not specified)

the paper's co-authors, your dean, supervisor, Yes (Colleagues and co-authors; Supervisors; University staff or committees) tenure \& promotions committee)? Another researcher conducting work on predatory journals

Has the experience of publishing in a No potentially predatory journal affected how you Yes (not specified how)

evaluate future journals prior to submission? Will check details about the journal (Will be more careful; Check impact factor: If yes, how? editor: Check peer review process; Check citations; Check Beall's list; Check open source journals

Consult with others (Colleagues; University management; Scientific committee; Supervisor)

Will only publish in known/prestigious/authentic journals

Not publish in open access journals

Fees

Suggestions

DOI, digital object identifier; ISSN, International Standard Serial Number. 
factoring in rejection.' One participant (1.2\%) noted the importance of supporting new and small journals.

When asked about other motivations for publishing in the selected journal, several participants expressed frustration with 'traditional' journals, noting very long 'time to publication' periods, high fees, unnecessarily critical peer review and a bias toward publishing only the work of well-known researchers. One respondent captured the sentiment:

Open access is great. Other journals have too much unjustified criticism in their peer review process. Quite often even excellent articles are rejected while mediocre or trivial papers of well-known scientists or people of their lab are published. Many people think that quality journals operate [with] nepotism.

\section{Learning about the journal's Predatory Nature}

Twenty-four participants (28.3\%) reported that our survey was the first time they learnt the journal was potentially predatory. Thirteen participants $(15.9 \%)$ disagreed that the journal was predatory and provided reasons such as: 'I received peer review first,' 'It took over 3 months before my manuscript was published,' and, '[The journal] is accepted by the university.' Those that did agree the journal was predatory, and learnt about its nature prior to the survey, said they learnt it was predatory because of hidden fees or unusual payment processes, publication processes (eg, incoherent or non-critical peer review, atypical correspondence), a list of predatory journals, or a lack of journal indexing.

Participants were also asked if anyone discussed the predatory nature of the journal with them. Sixty-one participants $(74.4 \%)$ said no. The remaining participants $(\mathrm{n}=21,25.6 \%)$ were approached by colleagues and co-authors, supervisors, or university staff. One participant $(1.2 \%)$ responded they were approached ' $\ldots$ only [by] close colleagues, who thought I had finished my research career, perhaps implying their perspectives of the risks of publishing in presumed predatory journals.

\section{Career risks}

Most participants $(\mathrm{n}=54,65.9 \%)$ reported not experiencing any career risks related to publishing in a potentially predatoryjournal. The remaining participants $(n=28$, $34.1 \%$ ) noted that they were reprimanded by their supervisor, received few citations of their paper, experienced damage to their reputation, and missed the opportunity of helpful peer review. Two participants (2\%) reported having attempted to retract the article by contacting the journal, but the articles were still published.

\section{Evaluating future journals prior to submission}

Nineteen participants (23.2\%) reported that the experience of publishing in a presumed predatory journal has not changed how they evaluate journals prior to submitting other articles. The other participants $(\mathrm{n}=63,76.8 \%)$ stated they would be more careful in future journal selection by checking the impact factor, a digital object identifier or International Standard Serial Number, journal indexing, background of the editor, peer review process, citations, Beall's list or with others (eg, colleagues, university management, supervisors). Some participants shared that the experience has taught them never to pay for publication, to only publish in well-known journals and not to publish in open-access journals.

\section{DISCUSSION}

This research is among the first to survey a geographically diverse group of biomedical researchers about their motivations and experiences of submitting to, and publishing in, presumed predatory journals. The most striking finding of our survey is that the vast majority of respondents reported receiving peer review feedback that they found to be substantive in nature. A strongly held belief is that predatory journals generally do not provide peer review and, if they do, it is frivolous and/or minimal and does not add to the scientific integrity of article; indeed, this characteristic has been proposed as an important differentiator between presumed predatory journals and legitimate open access journals. Previous research confirms that articles published in predatory journals are of very low quality compared with research published in legitimate open access journals. ${ }^{7}$ To more fully understand the respondents' peer reviews requires access to them. While more than a quarter of the respondents indicated their willingness to share their peer reviews, only two did so, and one was an article proof rather than a peer review.

More than a third of the respondents indicated that they did not pay an article processing fee to publish their article. Previous research found similar results in a comparison of presumed predatory journals and legitimate open access journals. ${ }^{18}$ More than half the respondents identified themselves as university professors or as researchers working in a research institute. Most of them indicated that their institutions do not have policies in place to deter them and others from submitting to predatory publishers and journals. The respondents also highlighted the pressure to publish as part of their promotion and tenure assessment. The qualitative analysis shed light on participants' motivations and experiences of publishing in a predatory journal. It was clear that many participants did not agree that the journal in which they published was predatory. We perceived many participants felt strongly about this based on repetitive, emotionally-charged responses to the open-ended questions.

Our survey differs from previous efforts. For example, we focused on authors publishing biomedical articles whereas Kurt sought a broad spectrum of disciplines. ${ }^{10}$ Kurt's results also differed from ours in that of his four thematic results, social identify threat, unawareness, high pressure and lack of research proficiency, only high pressure to publish and unawareness were also identified by us and two of these two motivators have also been identified by others. ${ }^{19}$ Of the 
480 researchers from India who were identified as having published in a presumed predatory journal, more than $70 \%$ reported having pressure to publish research articles to facilitate career promotions and job security. Only $10 \%$ of respondents reported being aware that their relevant article was published in a predatory journal; however, more than $70 \%$ were not willing to answer this question. In addition to professors feeling pressure to publish, many reported submitting to presumed predatory journals to help students publish. In several parts of the world it is common for students to complete manuscript-based PhDs, and without publications it is not possible for them to graduate. In the online survey of researchers from India, an institutional requirement of between one and three publications as a criterion for their $\mathrm{PhD}$ defence was reported by $90 \%$ of the respondents. What is troubling here is that students may model their professor's behaviour and actively engage in submitting to predatory journals as a goal from the inception of their career. Understanding the motivations that lead authors to submit to a predatory journal, whether intentionally or unintentionally, is important from the perspective of both academic institutions and research funders. We encourage stakeholders to examine the guidelines used in our research institute to raise awareness and help deter prospective authors from submitting to predatory journals. The policy is freely available using a creative common license for easy reuse and modification (see https://osf.io/tvz4a/).

Our response rate was lower than that reported by others surveying this community. ${ }^{9}{ }^{10}$ It is possible that our initial survey was not conducted with an optimal temporal relationship to the identified published article; there was a time lag between publication and sending out the survey. We tried to counter this with our second survey but we only achieved a modest increase in the response rate. It is possible that biomedical researchers are more reluctant to discuss presumed predatory journals compared with researchers from other disciplines. This likely requires additional inquiry. We found it difficult to interpret some free text survey responses, perhaps signalling that English was not the first language of some respondents. It is possible that our results are influenced by cognitive bias given the nature of our questions and the content we are inquiring about, namely, presumed predatory journals; it is unclear whether all of the journals included in our analyses were predatory and this is another limitation of our survey. Our survey is also based on self-reported data; this is a limitation. Further, some of these journals may not be predatory. There is no consensus on which characteristics or set of characteristics constitute predation. Empirical data, such as the presentation of false metrics between journals listed on Directory of Open Access Journals (DOAJ) compared with those not listed there is likely important in distinguishing between deceptive and legitimate journals. It is difficult to adjust survey responses for such bias. Future surveys as to the motivations for publishing in these journals should develop questions that minimise or avoid cognitive bias.
We focused on biomedical research as this is the discipline most relevant to the co-author team and because of the implications that publishing biomedical research can have on patients and clinical care. There is accumulating evidence that articles published in predatory journals are leaking into trusted sources of information, such as PubMed..$^{20}$ It is unclear whether such articles end up in systematic reviews or clinical practice guidelines which impact clinical practice and health policies. This also requires additional investigation. Finally, our survey results need to be interpreted in the light of their being based on self-reported responses.

While these results are informative, and provocative in places, adding to the knowledge base of presumed predatory publishers and journals, they do not provide a complete picture regarding the motivations to publish in presumed predatory journals. Knowledge of researcher motivations to publish in predatory journals is critical in order to be able to develop effective interventions to prevent future submissions. For example, if researchers are intentionally using these outlets as a means to pad their CVs, outreach and education is unlikely to effectively stop future submissions. However, educational outreach to hiring, promotion and tenure committees might be useful. In contrast, if researchers are being duped, or because of their lack of knowledge on issues with predatory journals, outreach and training may be an appropriate intervention. The outcomes from this work may have important implications for policy development and on actions to thwart presumed predatory journals

Addressing these, and other related questions, requires resources. To date funders have not indicated their interest in funding investigations into predatory journals. This is unfortunate and, perhaps, short-sighted. Data indicate a steep upward trajectory in the number of research articles published in predatory journals (even though this represents a very small fraction of the total number of biomedical publications). Some research ending up in predatory journals is funded. This is likely a bad investment in what for most funders is a limited fiscal budget. We recommend that funders give more serious consideration to funding research in predatory journals and act to promptly develop relevant policy. Other players also need to be involved in helping to weed out predatory publishers and journals. ${ }^{6}$

\section{Author affiliations}

${ }^{1}$ Centre for Journalology, Ottawa Hospital Research Institute, Ottawa, Ontario, Canada

${ }^{2}$ School of Epidemiology and Public Health, University of Ottawa Faculty of Medicine, Ottawa, Ontario, Canada

${ }^{3}$ University of Ottawa Telfer School of Management, Ottawa, Ontario, Canada ${ }^{4}$ Department of Research, Institut du Savoir Monfort, Ottawa, Ontario, Canada ${ }^{5}$ Department of Clinical Epidemiology, Ottawa Hospital Research Institute, Ottawa, Ontario, Canada

${ }^{6}$ Department of Psychiatry, Lady Davis Institute, Jewish General Hospital, Montreal, Quebec, Canada

${ }^{7}$ Department of Psychology, McGill University, Montreal, Quebec, Canada ${ }^{8}$ Department of Biomedical Engineering, University of Waterloo Faculty of Engineering, Waterloo, Ontario, Canada 
${ }^{9}$ Ottawa Methods Centre, Ottawa Hospital Research Institute, Ottawa, Ontario, Canada

Acknowledgements We are grateful to Raymond Daniel who helped upload journal names and URL's into DistillerSR for review and reference formatting.

Contributors KDC, DM and MML conceived of the study idea. KDC, DM, AG and MML wrote the study protocol and designed the study survey. KDC, HR, DBR and AG identified the sample and extracted information related to corresponding authors. HR and KDC sent the e-mail to the sample of participants. KDC, AG and DBR conducted the study analysis. KDC, $A G$ and DBR wrote the initial draft of the article. All authors provided critical feedback and agreed to the final version of the paper. DM provided funding for participant reimbursement costs.

Funding DBR is supported by a Canadian Institutes of Health Research Vanier Graduate Scholarship. DM provided funding for participant reimbursement costs. AG provided funding for open access publication fees. MML is supported by The Ottawa Hospital Anesthesia Alternate Funds Association and the Scholarship Protected Time Program, Department of Anesthesiology and Pain Medicine, Ottawa.

Competing interests None declared.

Patient consent for publication Not required.

Ethics approval This study received ethical approval from the Ottawa Health Science Network Research Ethics Board (20170956-01H; see https://osf.io/xaze9/).

Provenance and peer review Not commissioned; externally peer reviewed.

Data sharing statement Data screening and extraction forms, as well as random samples of journals, can be found on the OSF: https://osf.io/jy3vh/. Each survey question, theme, and participant responses can be found in the OSF (https://osf.io/ xrstp/).

Open access This is an open access article distributed in accordance with the Creative Commons Attribution Non Commercial (CC BY-NC 4.0) license, which permits others to distribute, remix, adapt, build upon this work non-commercially, and license their derivative works on different terms, provided the original work is properly cited, appropriate credit is given, any changes made indicated, and the use is non-commercial. See: http://creativecommons.org/licenses/by-nc/4.0/.

\section{REFERENCES}

1. Moher D, Srivastava A. You are invited to submit. BMC Med 2015;13:180.
2. Clemons $M$, de Costa E Silva M, Joy AA, et al. Predatory invitations from journals: more than just a nuisance? Oncologist 2017;22:236-40.

3. Beall J. Predatory publishers are corrupting open access. Nature 2012;489:179.

4. Beall J. Predatory publishing is just one of the consequences of gold open access. Learned Publishing 2013;26:79-83.

5. Bohannon J. Who's afraid of peer review? Science 2013;342:60-5.

6. Lalu MM, Shamseer L, Cobey KD, et al. How stakeholders can respond to the rise of predatory journals. Nat Hum Behav 2017;1:852-5.

7. Moher D, Shamseer L, Cobey KD, et al. Stop this waste of people, animals and money. Nature 2017;549:23-5.

8. Cobey KD, Lalu MM, Skidmore B, et al. What is a predatory journal? A scoping review. F1000 2018;7.

9. Bagues M, Sylos-Labini M, Zinovyeva N. A walk on the wild side: an investigation into the quantity and quality of 'predatory ' publications in Italian academia. Pisa, Italy: LEM Working Paper Series, No. 2017/01, Scuola Superiore Sant'Anna, Laboratory of Economics and Management (LEM), 2016.

10. Kurt S. Why do authors publish in predatory journals? Learned Publishing 2018;31:141-7.

11. Beall J. Beall's List: potential, possible, or probable predatory scholarly open-access publishers. https://scholarlyoa.com/ publishers/

12. Oransky I. Why did Beall's List of potential predatory publishers go dark? Retraction Watch. 2017 https://retractionwatch.com/2017/01/ 17/bealls-list-potential-predatory-publishers-go-dark/

13. Fact SheetMEDLINE $®$ Journal Selection. U.S. National library of medicine. https://www.nlm.nih.gov/lstrc/jsel.html

14. Beall J, Levine R. OMICS goes from "predatory publishing" to "predatory meetings" Scholarly Open Access. 2013 https:// scholarlyoa.com/2013/01/25/omics-predatory-meetings/

15. Han AP. US court issues injunction against OMICS to stop "deceptive practices." Retraction Watch. 2017.

16. Survey Monkey. SurveyMonkey. https://www.surveymonkey.com/

17. Hsieh HF, Shannon SE. Three approaches to qualitative content analysis. Qual Health Res 2005;15:1277-88.

18. Shamseer L, Moher D, Maduekwe O, et al. Potential predatory and legitimate biomedical journals: can you tell the difference? A crosssectional comparison. BMC Med 2017;15:28.

19. Seethapathy GS, Santhosh Kumar JU, Hareesha AS. India's scientific publication in predatory journals:need for regulating quality of indian science and education. Curr Sci 2016;111:1759-64.

20. Manca A, Moher D, Cugusi L, et al. How predatory journals leak into PubMed. CMAJ 2018;190:E1042-5. 